\title{
Retrograde intubation in a patient with neglected cervical spine injury for sacral advancement flap
}

\author{
B Sriramka ${ }^{1^{*}}$, SK Pattnaik ${ }^{2}$, \\ Senior Resident ${ }^{*}$, Associate Professor ${ }^{2}$ \\ Department of Anesthesia \& Critical Care IMS \& SUM Medical College \& Hospital, Bhubaneswar, \\ Odisha, India.
}

\begin{abstract}
Neglected cervical spine injury is a challenging scenario for an anaesthetist. Fixed deformities, altered local anatomy, fear of neurological worsening makes intubation difficult and prevents use of manoeuvers in classical intubation. Advances in equipment like fiberoptic bronchoscope or the video laryngoscope aid in such situations. Retrograde intubation (RI) is a useful alternative with high success rate in safe and experienced personnel. The purpose of the article is to highlight the use of this slowly becoming antique technique which becomes quite handy in difficult airway situations.
\end{abstract}

Keywords: Neglected cervical injury; flexion deformity of neck; retrograde intubation; difficult airway

\section{Introduction}

Altered neck anatomy is a very important predictor of a difficult airway and securing the airway in patients requiring general anesthesia is challenging. ${ }^{1}$ Retrograde tracheal intubation is a useful alternative technique which can be accomplished without head and neck movement and has a high success rate in experienced hands. We herein report a case of neglected cervical spine injury with flexion deformity of neck scheduled for sacral advancement flap.

\section{Case report}

A 28yr old male electrician had fallen from a height 3 months ago while working and sustained cervico thoracic injuries leading to paraparesis and chest injuries. The patient was treated elsewhere with thoracic fixation and was managed in intensive care on ventilatory support with tracheostomy.

\section{*Correspondence: B Sriramka \\ E mail: bhavna.sriramka@gmail.com}

0000-0001-8439-5908

Received: 09/05/2017

Accepted: 14/05/2017

DOI: 10.4038 /slja.v25i2.8235

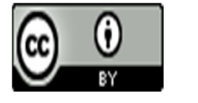

The cervical spine was not operated as probably neurology was intact in upper limb and patient had a high morbidity due to polytrauma. The tracheostomy tube was removed and patient was discharged in stable condition though neurological improvement was not there. Subsequently the patient developed a pressure sore in the sacral area and was admitted for its management.

He was about $52 \mathrm{~kg}$ with BMI $27.8 \mathrm{~kg} / \mathrm{m}^{2}$, conscious and cooperative. He had a lateral flexion deformity in neck with head tilted to right and chin facing left. (Figure 1a).
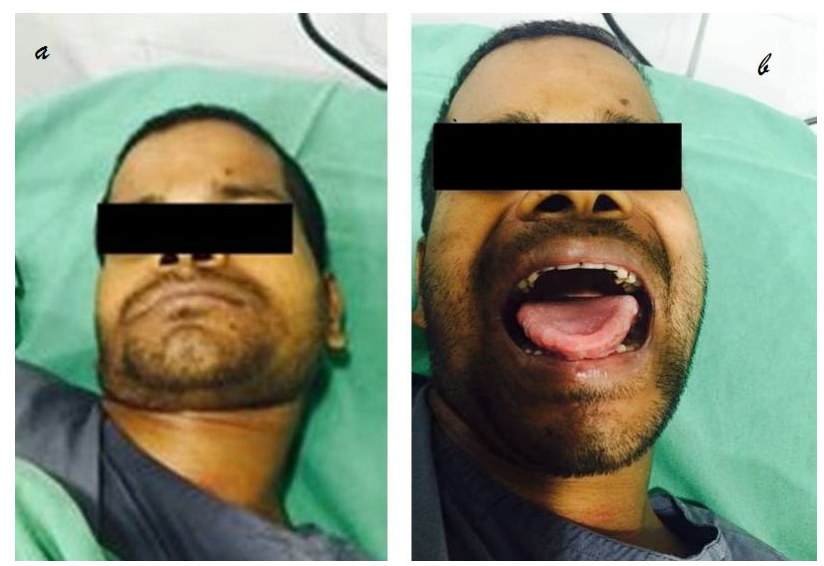

Figure 1a and 1b

Neck movements were severely restricted. Examination of airway revealed an adequate mouth opening with Mallampati grading of 2 (Figure1b). Chest expansion was normal. His lower limb motor power was MRC grading $<2 / 5$ but sensory system 
was intact. He had a single sacral sore measuring $6 \times 7 \mathrm{~cm}$ in the midline and was scheduled by our plastic surgeon for an advancement flap. On ENT consultation, nasal passages were normal but vocal cords were not visible on indirect laryngoscopy. All routine and special investigations and pulmonary function tests were within normal limits. X-ray neck antero-posterior and lateral view showed a unilateral facetal dislocation at C5-6 level with mild sublaxation of spine at the same level (Figure 2a, $2 \mathrm{~b})$. The trachea seems deviated with a normal width.
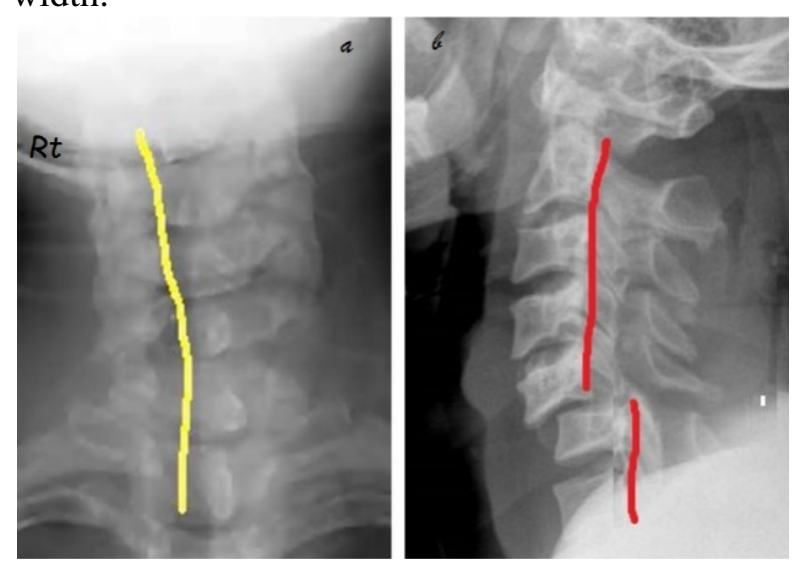

Figures 2a and 2b

The procedure for retrograde intubation was planned and informed consent was taken for a possible emergency tracheostomy if needed. Patient was nebulised with $4 \%$ lignocaine to suppress the airway reflexes. Premedication with $0.2 \mathrm{mg}$ of glycopyrrolate, $1 \mathrm{mg}$ of midazolam and $100 \mathrm{mcg}$ of fentanyl injection i.v. were given. Preoxygenation was done with $100 \%$ oxygen for 5 mins following which patient was sedated with propofol $2 \mathrm{mg} / \mathrm{kg}$ i.v. Under aseptic precautions, cricothyroid membrane was infiltrated with $1 \mathrm{ml} 2 \%$ lignocaine and penetrated with a $16 \mathrm{G}$ epidural tuohy needle. Tracheal puncture was confirmed by aspiration of air and $1.5 \mathrm{ml}$ of lignocaine $2 \%$ was injected. A central line guide wire was passed through the needle and retrieved orally with the help of laryngoscopy and Magill's forceps. Flexometallic $8 \mathrm{~mm}$ internal diameter tube was rail roaded over the guide wire. Confirmation of endotracheal tube position was done by auscultation and capnography and ET tube was secured. Anaesthesia was maintained with isoflurane and atracurium. Neck was supported and prone positioning was done carefully maintaining the neck immobilization with rolled OT sheets on the sides. Surgery lasted for 2 hours and was uneventful. On completion the patient was made supine and anaesthesia was reversed with neostigmine $50 \mathrm{mcg} / \mathrm{kg}$ and glycopyrrolate 10 $\mathrm{mcg} / \mathrm{kg}$ i.v., and extubated. Patient was shifted to high dependency unit for post-operative observation.

\section{Discussion}

Cervical spine injury is a difficult airway situation.Efforts to secure airway in these patients may worsen the subluxation leading to aggravation of the neurological deficit. Securing the airway of such a patient is a challenge to the anaesthetist. Newer developments in equipment for intubation such as fibreoptic bronchoscope, laryngeal mask airway and video laryngoscope have opened new doors for safe intubation in difficult scenarios. However retrograde intubation remains the classic technique with good success rate in experienced hands for the management of predictable and nonpredictable difficult airways. $^{2}$

Challenges for securing the airway in our case were many- neglected cervical spine injury leading to a flexion deformity of neck, post tracheostomy, alteration of local anatomy and requirement for a prone position for the surgery. We planned for a retrograde intubation in sedated and spontaneously ventilated patient owing to unavailability of fibreoptic bronchoscope in our set up. Studies have shown that chin lift, jaw thrust or even simple cricoid pressure is associated with displacement of spine hence we had to be careful to omit these procedures. ${ }^{3}$ Altered anatomy also precluded us from giving local nerve blocks. To make the procedure safe we nebulised with local anaesthetics and sedated the patient. We used a central line guide wire with tuohy needle, which were readily available.

There have been a lot of modifications to retrograde intubation since it was originally described by Butler and Cirillo in $1960 .{ }^{4}$ Although there are some known complications ${ }^{5}$ like airway trauma, bleeding from nose/cricothyrotomy site, subcutaneous emphysema, infections and even variable success rates among practitioners ${ }^{6}$; we did not encounter any problem. Recent advances of retrograde intubation and the combined use with fiber optic 
bronchoscope ${ }^{7}$, or ultrasound guidance ${ }^{8}$ have renewed interest in this old technique.

\section{Conclusion}

Retrograde intubation is a simple and useful technique, with commonly available equipments and can be performed safely in experienced hands. Besides it has a high level of skill retention, hence it is always a useful alternative to fibre optic bronchoscope and avoids tracheostomy when faced with a difficult airway situation.

\section{References}

1. Benum of JL. Definition and incidence of difficult airway. In: Benum of JL. Editor. Airway management: Principles and practice. St Louis Mosby 1996: 121-125

2. American Society of Anesthesiologists Task Force on Management of the Difficult Airway. Practice guidelines for management of the difficult airway. A report by the American Society of Anesthesiologists Task Force on Management of the Difficult Airway. Anesthesiology 1993 Mar; 78(3):597-602.

https://doi.org/10.1097/00000542-19930300000028

3. Aprahamian C, Thompson BM, Finger WA, Darin JC. Experimental cervical spine injury model; evaluation of airway management and splinting techniques. Ann Emerg Med. 1984; 13: 584-587. https://doi.org/10.1016/S0196-0644(84)80278-4

4. Butler FS, Cirillo AA. Retrograde tracheal intubation. AnesthAnalg1960;39:333-8. https://doi.org/10.1213/00000539-19600700000013 PMid:13806479

5. Gill M, Madden MJ, Green SM. Retrograde endotracheal intubation: An investigation of indications, complications, and patient outcomes. Am J Emerg Med 2005;23:123-6. https://doi.org/10.1016/j.ajem.2004.03.002 PMid:15765328

6. Burbulys D, Kiai K. Retrograde intubation. Emerg Med Clin North Am 2008 Nov;26(4):1029-41. https://doi.org/10.1016/j.emc.2008.08.007

PMid:19059099

7. Varshney PG, Kachru N. Fibreoptic-aided retrograde intubation: Is it useful to combine two techniques? Indian J Anaesth 2011; 55:546-7. https://doi.org/10.4103/0019-5049.89908

PMid:22174484 PMCid:PMC3237167

8. Vieira D, Lages N, Dias J, Maria L, Correia C. Ultrasound-guided retrograde intubation. Anaesthesia2013;68:1075-6. https://doi.org/10.1111/anae.12430 